\title{
Atividade antimicrobiana da Melaleuca alternifolia e sua aplicação na Odontologia
}

Antimicrobial activity of Melaleuca alternifolia and its application in Dentistry

Actividad antimicrobiana de Melaleuca alternifolia y su aplicación en Odontología

Lorena Thays Rodrigues SAMPAIO ${ }^{1}$

Heloísa Mara Batista Fernandes de OLIVEIRA²

Abrahão Alves de OLIVEIRA FILHO ${ }^{3}$

${ }^{1}$ Curso de Graduação em Odontologia da Universidade Federal de Campina Grande, UFCG, campus de Patos 58708-110, Patos-PB, Brasil

2Farmacêutica-Bioquímica, Hospital Universitário Ana Bezerra (HUAB), UFRN, campus de Santa Cruz 59.200-000, Santa Cruz-RN, Brasil

${ }^{3}$ Professor Doutor, Unidade Acadêmica de Ciências Biológicas, Centro de Saúde e Tecnologia Rural, Universidade Federal de Campina Grande UFCG 58428-830 Campina Grande - PB, Brasil

\section{Resumo}

Introdução: As bactérias são seres que podem habitar a microbiota normal humana e também podem desencadear infecções. A cavidade oral é colonizada por milhares de microrganismos e o aumento da resistência bacteriana sugere alternativas à utilização de antibióticos. Estudos com a Melaleuca alternifolia têm demonstrado sua ação antimicrobiana sobre esses microrganismos e potenciais usos na odontologia. Objetivo: realizar uma revisão sobre os aspectos botânicos e farmacológicos da Melaleuca alternifolia e sua aplicação como antimicrobiano na odontologia. Material e método: Trata-se de uma revisão narrativa de literatura. Os dados foram coletados de 16 de setembro a 04 de outubro de 2019 nas plataformas Google Acadêmico, SciELO, PubMed e periódicos CAPES, utilizando os descritores: Melaleuca alternifolia, antimicrobiano, fitoterapia e odontologia. Todos os artigos foram analisados e apresentaram a temática elencada para a pesquisa. Resultados e discussão: A Melaleuca alternifolia, também conhecida como árvore do chá é uma planta nativa da Austrália, pertencente à família Myrtaceae, apresentando ação bactericida principalmente devido ao terpinen-4-ol, principal constituinte químico do óleo essencial da planta, o qual tem demonstrado ação sobre Streptococcus mutans e Enterococccus faecalis, dentre outros microrganismos, incluindo vírus e leveduras, podendo ser aplicado na prevenção da doença cárie, como enxaguatórios bucais e como coadjuvante no tratamento endodôntico. Conclusão: Portanto, a utilização da Melaleuca alternifolia para tratar doenças decorrentes de infecções bacterianas na Odontologia é de excelente escolha, no entanto, é necessário mais estudos a cerca dos constituintes químicos da planta.

Descritores: Fitoterapia; Farmacologia; Microbiologia.

\section{Abstract}

Introduction: Bacteria are beings that can inhabit the normal human microbiota and can also trigger infections. The oral cavity is colonized by thousands of microorganisms and increased bacterial resistance suggests alternatives to the use of antibiotics. Studies with Melaleuca alternifolia have demonstrated its antimicrobial action on these microorganisms and potential uses in dentistry. Objective: To review the botanical and pharmacological aspects of Melaleuca alternifolia and its application as antimicrobial in dentistry. Material and method: This is a narrative literature review. Data were collected from September 16 to October 04, 2019 in the Google Scholar, SciELO, PubMed and CAPES journals platforms, using the keywords: Melaleuca alternifolia, antimicrobial, herbal medicine and dentistry. All articles were analyzed and presented the theme listed for the research. Results and discussion: Melaleuca alternifolia, also known as tea tree, is a native plant from Australia, belonging to the Myrtaceae family, showing bactericidal action mainly due to terpinen-4-ol, the main chemical constituent of tea tree oil, which has demonstrated action on Streptococcus mutans and Enterococccus faecalis, among other microorganisms, including viruses and yeasts, and can be applied in the prevention of caries disease, as mouthwash and as an adjuvant in endodontic treatment. Conclusion: Therefore, the use of Melaleuca alternifolia to treat diseases resulting from bacterial infections in Dentistry is an excellent choice. However, further studies are needed on the chemical constituents of the plant.

Descriptors: Phytotherapy; Pharmacology; Microbiology.

\section{Resumen}

Introducción: las bacterias son seres que pueden habitar la microbiota humana normal y también pueden desencadenar infecciones. La cavidad oral está colonizada por miles de microorganismos y el aumento de la resistencia bacteriana sugiere alternativas al uso de antibióticos. Los estudios con Melaleuca alternifolia han demostrado su acción antimicrobiana en estos microorganismos y sus posibles usos en odontología. Objetivo: Revisar los aspectos botánicos y farmacológicos de Melaleuca alternifolia y su aplicación como antimicrobiano en odontología. Material y método: Esta es una revisión de literatura narrativa. Los datos se recopilaron del 16 de septiembre al 4 de octubre de 2019 en las plataformas de revistas Google Scholar, SciELO, PubMed y CAPES, utilizando las palabras clave: Melaleuca alternifolia, antimicrobiana, fitoterapia y odontología. Todos los artículos fueron analizados y presentaron el tema enumerado para la investigación. Resultados y discusión: Melaleuca alternifolia, también conocida como árbol de té, es una planta nativa de Australia, perteneciente a la familia Myrtaceae, que muestra acción bactericida principalmente debido a terpinen-4-ol, el principal componente químico del aceite esencial de la planta, que ha mostrado acción sobre Streptococcus mutans y Enterococccus faecalis, entre otros microorganismos, incluidos virus y levaduras, y puede aplicarse en la prevención de la enfermedad de caries, como enjuague bucal y como adyuvante en el tratamiento endodóntico. Conclusión: Por lo tanto, el uso de Melaleuca alternifolia para tratar enfermedades resultantes de infecciones bacterianas en Odontología es una excelente opción, sin embargo, se necesitan más estudios sobre los componentes químicos de la planta.

Descriptores: Fitoterapia; Farmacología; Microbiología.

INTRODUÇÃO

As bactérias são seres procariontes, ou seja, desprovidos de membrana nuclear (carioteca) e não possuem todas as estruturas internas das células eucariontes, sendo mais simples em todos os aspectos, com exceção do seu envoltório celular ${ }^{1}$. Esses microrganismos variam em tamanho entre 0,2 e $5 \mu \mathrm{m}$, sendo os menores organismos capazes de existir fora de um hospedeiro e apresentam uma parede celular, localizada externamente à membrana citoplasmática, a qual é composta por peptideoglicanos, estrutura responsável pelo suporte e manutenção da célula bacteriana. ${ }^{2}$

As bactérias podem ser classificadas também quanto a sua patogenicidade em comensais, as quais habitam a microbiota 
normal humana, e em patogênicas, as quais são responsáveis por desencadear infecções bacterianas $^{2}$. Essas infecções podem ser classificadas de acordo com a extensão em que o organismo do hospedeiro é afetado, podendo ser locais ou generalizadas, nesse caso representadas pela septicemia ou bacteremia, além de outras doenças, as quais são consideradas emergentes, tais como a coqueluche, pneumonia, infecções do trato urinário e endocardites ${ }^{3}$.

No âmbito odontológico, a cavidade oral é colonizada por milhares de microrganismos, envolvendo uma grande diversidade de espécies, que estabelecem uma relação harmônica com o sistema imune do hospedeiro, de modo que havendo um desequilíbrio na flora bacteriana do indivíduo ou ocorrendo incorporação de um microrganismo externo, desenvolve-se um quadro de infecção ${ }^{4}$. As infecções que atingem os espaços da cabeça e pescoço são processos disseminativos através dos espaços fasciais desta região e podem ser divididas em infecções superficiais ou profundas, sendo a maior parte destas infecções associada a focos de origem dentária, causadas por lesões de cárie ou pericoronarite ${ }^{5}$.

De acordo com a Organização Mundial (OMS), aproximadamente $80 \%$ da população mundial utilizam a medicina alternativa, destacando-se os medicamentos fitoterápicos, para suprir a ausência de atendimento médico primário, principalmente em países da África, no entanto, os medicamentos de origem vegetal também são populares em países desenvolvidos como França e Alemanha, de modo que se destacam suas utilizações nos tratamentos de resfriados, gripes e problemas intestinais ${ }^{6}$.

As pesquisas com produtos naturais (fitoterápicos) têm aumentado nos últimos anos na área odontológica, devido à busca por produtos com maior atividade farmacológica?. Além disso, tem se observado a evolução da resistência bacteriana, o que está gerando um grave problema de saúde pública decorrente do uso indiscriminado de antibióticos, o que torna importante gerar estratégias que contribuam para diminuí-la ${ }^{7}$. Estudos mostram que espécies como Cravo da Índia, Romã, entre outras, podem ser usadas nos casos de abscesso bucais, apresentado ação bactericida e bacteriostática sobre bactérias Gram-positivas e Gram-negativas, que compõem o biofilme dental $^{9}$.

A Melaleuca alternifolia, planta nativa da Austrália, também conhecida como árvore do chá, possui boas propriedades antimicrobianas $^{10}$. Estudos realizados com óleos essenciais naturais indicam que 0 óleo essencial de melaleuca pode ser usado como antimicrobiano ${ }^{11}$. Portanto, 0 objetivo do presente estudo foi realizar uma breve revisão bibliográfica sobre os aspectos botânicos e farmacológicos da espécie Melaleuca alternifolia e sua aplicação como antimicrobiano no tratamento de infecções e doenças bacterianas que acometem a cavidade oral.

MATERIAL E MÉTODO

O presente estudo trata-se de uma revisão narrativa da literatura, no qual foi realizada uma seleção de artigos científicos recuperados a partir das bases de dados: Scielo (Scientific Eletronic Library Online), Googe Acadêmico, PubMed (Biblioteca Nacional de Medicina dos Estados Unidos) e Periódicos CAPES, apresentando informações confiáveis e publicados em bases de dados no período de 2009 a 2019.

A pesquisa foi realizada de 16 de setembro a 04 de outubro de 2019 , nos idiomas português $e$ inglês. A estratégia de busca utilizada para pesquisa nas bases de dados se deu pela utilização dos seguintes descritores isolados ou em combinação, nas linguagem português e inglês: "Melaleuca alternifolia", "características botânicas", "constituintes químicos", "antimicrobiano", "fitoterapia", "odontologia", "óleo essencial", "árvore do chá", sendo selecionados 15 artigos científicos e 3 livros como amostra, os quais foram analisados e apresentaram a temática elencada para a pesquisa.

RESULTADOS E DISCUSSÃO

- Características botânicas da Melaleuca
alternifolia

Melaleuca é um gênero pertencente à família Myrtaceae e inclui aproximadamente 100 espécies nativas da Austrália e ilhas do Oceano Índico, dentre elas, a Melaleuca alternifolia, que é popularmente conhecida na Austrália como "árvore de chá", florescendo principalmente em áreas de pântano, próximas a rios, tendo como principal produto o óleo essencial (TTO - tea tree oil), extraído da planta por destilação a vapor, sendo de grande importância medicinal, pois possui comprovada ação bactericida e antifúngica contra vários patógenos humanos ${ }^{6}$.

As árvores dessa espécie podem atingir sete metros de altura, apresentando uma casca fina $^{12}$. Suas folhas são simples, coriáceas, agudas-lanceoladas e, algumas vezes, em formato de foice, de 1,0 a 2,5 centímetros de comprimento, apresentando glândulas de óleo ${ }^{13}$. Um dos principais fatores que dificultam 0 
cultivo de $M$. alternifolia em larga escala é a produção de mudas de qualidade, pois embora a plantação por sementes seja possível, esta técnica é bastante trabalhosa, já que suas sementes são muito pequenas, dificultando o processo de coleta ${ }^{14}$.

- Constituintes químicos do óleo essencial de Melaleuca alternifolia

Os óleos essenciais são líquidos oleosos aromáticos retirados de extratos vegetais, cuja atividade antimicrobiana é devida a vários terpenoides e compostos fenólicos pequenos ${ }^{15}$. O TTO possui aproximadamente 100 componentes, sendo que se destaca 0 terpinen-4-ol, terpeno presente em 30 a $40 \%$ da sua composição, apresentando a principal atividade antimicrobiana, pois induz a perda de membrana bacteriana, com consequente perda de material intracelular, ou seja, possui mecanismo de ação bactericida, levando a impossibilidade de se manter a hemostase, além de inibir a respiração celular ${ }^{12}$.

Além do terpinen-4-ol, outros constituintes químicos presentes no TTO são o gama-terpieno, o a-terpieno, o a-pineno e o 1,8-cienol, sendo este último capaz de aumentar a permeabilidade da membrana, facilitando a entrada de outros agentes antimicrobianos; entretanto, por possuir cerca de 100 componentes, provavelmente não foi pesquisado todo o seu potencial de atuação, sendo que outros elementos podem não ter sido ainda avaliados ${ }^{12}$.

\section{- Potencial antimicrobiano da Melaleuca alternifolia}

Os óleos essenciais são extraídos das partes vegetativas da planta e são ricos em mono e sesquiterpenos, sendo que dentre suas atividades farmacológicas destaca-se a antimicrobiana, de modo que essas atividades vêm sendo reportadas na revisão de Hammer et al. ${ }^{15}$.

O TTO vem sendo empregado no mercado farmacêutico e cosmético como agente antimicrobiano, para tratar lesões, queimaduras, picadas de inseto, e até mesmo como dentifrícios, e é justamente por essa boa ação antimicrobiana e da sua diversificada utilização médica, que o TTO passou a ser empregado também na área odontológica ${ }^{6}$.

Vários agentes químicos sintéticos foram avaliados ao longo dos anos em relação a seus efeitos antimicrobianos contra a cárie dentária, porém todos estão associados a vários efeitos colaterais; assim, os pacientes estão preferindo usar preparações à base de plantas que sejam eficientes, porém com menos efeitos colaterais possíveis ${ }^{16}$.
Com a finalidade de diminuir o número de bactérias que colonizam a cavidade bucal, muitas substâncias químicas são empregadas, como o flúor, que é a substância mais eficaz no controle da doença cárie, apresentando ação antibacteriana e remineralizadora, no entanto, a exposição prolongada a altas concentrações de flúor no período de desenvolvimento dentário pode levar à fluorose dental, já a clorexidina, empregada no tratamento de doenças bucais, também causa problemas como manchamentos de superfícies e alteração da sensação gustativa; portanto, frente a esses problemas, sugere-se que o TTO possa ser útil na manutenção da higiene e prevenção de doenças bucais ${ }^{6}$.

Em estudo publicado por Brun et al. ${ }^{17}$, a atividade antimicrobiana e o perfil químico de dez produtos de TTO disponíveis no mercado foram analisados. A atividade antimicrobiana foi avaliada contra Candida glabrata, vírus Herpes simplex tipo 1 (HSV-1), Staphylococcus aureus resistente à meticilina (MRSA) e Pseudomonas aeruginosa cultivadas em modo planctônico ou em biofilmes, de modo que cinco em cada dez lotes de TTO relataram atividade antimicrobiana significativa, reduzindo a sobrevivência bacteriana nos biofilmes, gerarando danos oxidativos em $C$. glabrata e diminuindo a infectividade pelo HSV $-{ }^{17}$.

Estudos recentes sugeriram que várias bactérias expostos ao óleo essencial de melaleuca foram menos suscetíveis a antibióticos in vitro, o que seria preocupante, pois além de dificultar a eficácia dos antibióticos convencionais reduzindo a suscetibilidade das bactérias a esses antimicrobianos, poderia também influenciar 0 desenvolvimento de resistência. $^{15}$ Porém, segundo 0 estudo publicado por Hammer et al. ${ }^{15}$, onde foi testada a resistência a antibióticos sobre Staphylococcus aureus, Staphylococcus epidermidis e Escherichia coli, foi constatado que a exposição ao TTO não tem efeitos globais no desenvolvimento da resistência bacteriana, não havendo redução na suscetibilidade a antimicrobianos após exposição repetida ao terpinen-4-ol, concluindo-se que há poucas evidências para apoiar a preocupação de que o aumento do uso do TTO tanto nos ambientes domésticos, como nos de saúde, levará ao aumento da resistência antimicrobiana.

Ao analisar os resultados apresentados no estudo de Prestes et al. ${ }^{18}$, o qual avaliou a utilização do óleo essencial de melaleuca como coadjuvante no tratamento endodôntico, empregando o TTO em associação ao hidróxido de cálcio, se percebeu que o óleo essencial 
apresentou inibição satisfatória frente à Cândida albicans e também ao Enterecoccus faecalis, principais microrganismos envolvidos em infecções secundárias do sistema de canais radiculares e lesões perirradiculares.

Sinha et al. ${ }^{10}$ comprovaram em seu trabalho, a atividade antimicrobiana da melaleuca alternifolia frente ao Enterococcus faecalis e sugeriu que o extrato vegetal poderia ser uma alternativa ao hipoclorito de sódio, como produto irrigante do sistema de canais radiculares, porém destacou que para isso seriam necessários mais estudos, tais quais ensaios clínicos e pré-clínicos para outros parâmetros, como toxicidade e inibição da formação de biofilme.

No trabalho de Crispin e Lacerda ${ }^{12}$, um halo de inibição que chamou atenção foi o da Salmonella SS, formando $12 \mathrm{~mm}$ de diâmetro quando submetido ao óleo essencial puro de Melaleuca alternifolia, sendo o que mais se aproximou dos tamanhos dos halos padrões da ampicilina, podendo gerar uma ação bacteriolítica intermediária.

Prabhakar et al. ${ }^{16}$ avaliaram a eficácia e os efeitos adversos de enxaguatórios bucais em crianças, em concentrações de $2,5 \%$ de folhas de curry, $2,5 \%$ de alho e $0,2 \%$ de óleo de melaleuca sobre Streptococcus mutans e lactobacilos. Os enxaguatórios bucais com 2,5\% de folhas de curry, $2,5 \%$ de alho e $0,2 \%$ de óleo de melaleuca foram capazes de reduzir significativamente $\mathrm{S}$. mutans e lactobacilos, de modo que o TTO foi eficaz contra um alto número de bactérias gram-positivas e gramnegativas, bem como fungos, e apresentou menos efeitos adversos que os demais ${ }^{16}$.

A dificuldade de se padronizar um modelo experimental é um ponto muito importante e requer um amplo estudo, pois a falta de padronização para realização de estudos com óleos essenciais é algo que dificulta a comparação entre resultados, necessitando então uma padronização de métodos, meios de cultura, emulsificantes e densidade do inoculo para que estes estudos sejam realizados com mais precisão e eficiência ${ }^{12}$.

CONCLUSÃO

Diante do exposto, fica evidente que há uma necessidade de tratamentos alternativos na área odontológica, principalmente com relação às infecções bacterianas, devido o crescente aumento no índice de resistência aos antibióticos, de modo que a fitoterapia apresenta-se como uma estratégia para amenizar esse problema. A Melaleuca alternifolia possui ação antimicrobiana comprovada contra microrganismos patogênicos do biofilme bucal e, sobretudo, apresentando menos efeitos colaterais. Portanto, a utilização dessa espécie para tratar doenças decorrentes de infecções bacterianas na odontologia é de excelente escolha, no entanto, é necessário mais estudos a cerca dos constituintes químicos da planta.

\section{REFERÊNCIAS}

1. Nogueira JMR, Miguel LFS. Bacteriologia. In: Teva $A$ et al. Conceitos e métodos para a Formação de profissionais em laboratórios de saúde; 2009.

2. Levinson W. Microbiologia médica e imunologia. 13. ed. Porto Alegre: AMGH; 2016.

3. Tortora GJ, Funke, BR, Case CL. Microbiologia. 12. ed. São Paulo: Artmed; 2016.

4. Oliveira ILM, Ferreira ACA, Mangueira DFB, Mangueira LFB, Farias IAP. Antimicrobianos de uso odontológico: informação para uma boa prática. Odontol Clín.-Cient. 2011;10(3):217-20.

5. Conte Neto N, Spagnol G, Campos JADB, Gabrielli MAC, Pereira Filho VA. Infecções bacterianas da cabeça e pescoço: estudo retrospectivo. Rev Odonto. 2009;17(34):42-8.

6. Oliveira ACM, Fontana A, Negrini TC, Nogueira MNM, Bedran TBL, Andrade CR et al. Emprego do óleo de Melaleuca alternifolia Cheel (Myrtaceae) na odontologia: perspectivas quanto à utilização como antimicrobiano alternativo às doenças infecciosas de origem bucal. Rev Bras PI Med. 2011;13(4):492-99.

7. Cárdenas LL, Merchán, MA, Lopez DP. New antibiotics against bacterial resistance. Infectio.2019;23(4):352-57.

8. Francisco KSF. Fitoterapia: uma opção para o tratamento odontológico. Rev Saúde UNG. 2010;4(1):18-24.

9. Machado AC, Oliveira RC. Medicamentos Fitoterápicos na odontologia: evidências e perspectivas sobre o uso da aroeira-do-sertão (Myracrodruon urundeuva Allemão). Rev Bras PI Med. 2014;16(2):283-89.

10. Sinha DJ, Vasudeva A, Jaiswal N, Garg P, Tyagi SP, Singh J. Antibacterial efficacy of Melaleuca alternifólia (Tea tree oil), Curcuma longa (Turmeric), 2\% chlorhexidine, and 5\% sodium hypochlorite against Enterococcus faecalis: An in vitro study. Saudi Endod J. 2015;5(3):182-86.

11.Zhang X, Guo Y, Guo L, Jiang H, Ji Q. In Vitro Evaluation of Antioxidant and Antimicrobial Activities of Melaleuca alternifolia Essential Oil. Biomed Res Int. 2018; 2018:2396109.

12. Crispin GJB, Lacerda MCRN de. Análise da ação bacteriolítica da Melaleuca Alternifolia nas principais bactérias de interesse médico. 
Ensaios Cienc Cienc Biol Agrar Saúde. 2014; 18(2):67-75.

13. Monteiro MHDA, Macedo WH de, Silva Júnior A da, Paumgartten FJR. Óleos essenciais terapêuticos obtidos de espécies de Melaleuca L. (Myrtaceae Juss.). Rev Fitos. 2013; 18(1):1-72.

14. Stuepp CA, Pereira GP, Zem LM, Peña ML, Bueno PMC, Spader V et al. Enraizamento de melaleuca: Influência da altura de coleta das estacas e aplicação de IBA. Colloq agrar. 2013;9(1):1-9.

15. Hammer KA, Carson CF, Riley TV. Effects of Melaleuca alternifolia (tea tree) essential oil and the major monoterpene component terpinen-4ol on the development of single- and multistep antibiotic resistance and antimicrobial susceptibility. Antimicrob Agents Chemother. 2012;56(2):909-15.

16. Prabhaker AR, Vipin A, Basappa N. Effect of curry leaves, garlic and tea tree Oil on Streptococcus mutans and Lactobacilli in Children: A clinical and microbiological study. Pesqui bras odontopediatria clín integr. 2009;9(3):259-63.

17. Brun $P$, Bernabè G, Filippini R, Piovan A. In Vitro Antimicrobial Activities of Commercially Available Tea Tree (Melaleuca alternifolia) Essential Oils. Curr Microbiol. 2019;76(1): 108-16.

18. Prestes TS, Victorino FR. Atividade antimicrobiana do óleo de melaleuca associado ao hidróxido de cálcio. VIII EPCC - Encontro Internacional de Produção Científica Cesumar UNICESUMAR - Centro Universitário Cesumar. 2013.

\section{CONFLITO DE INTERESSES}

Os autores declaram não haver conflitos de interesse

\section{AUTOR PARA CORRESPONDÊNCIA}

\author{
Abrahão Alves de Oliveira Filho \\ Unidade Acadêmica de Ciências Biológicas do Centro \\ de Saúde e Tecnologia Rural da Universidade Federal \\ de Campina Grande \\ 58428-830 Campina Grande - PB, Brasil \\ E-mail: abrahao.farm@gmail.com
}

